\title{
Justicia Transicional en México: ¿Hacia la recon- figuración de la historia política?
}

\author{
María Patricia González Chávez*
}

$\boldsymbol{R}$ esumen

El presente artículo aborda las interrogantes presentes en México a partir del surgimiento del enfoque de la justicia transicional, poniendo especial atención en el impacto de la construcción democrática visto a la luz de la historiografía y con los derechos humanos como perspectiva. El argumento se centra en plantear que, en México aparece la justicia transicional como resultado de un contexto en el que convergen un sistema de alta y persistente violencia, junto a un legado de violaciones a los derechos humanos de la historia reciente, ante lo cual, diversos sectores hacen un llamado a que se atienda esta situación, ya que de no hacerlo, se compromete el Estado Democrático de Derecho. Desde esta perspectiva se revisa la historia reciente del país y los derechos humanos, las narrativas y ejercicios del tema como objeto de estudio, vistos desde la movilización e incidencia y el Estado mismo.

Palabras clave: Justicia Transicional, Democracia, Derechos Humanos, Historia politica reciente de México

\section{Transitional Justice in Mexico: Towards the reconfiguration of politi- cal history?}

\begin{abstract}
This article addresses the questions present in Mexico from the emergence of the transitional justice approach, with special attention to the impact of democratic construction seen in the light of historiography and with human rights as a perspective. The argument focuses on proposing that transitional justice appears in Mexico as a result of a context in which a system of high and persistent violence converge, along with a legacy of human rights violations in recent history, in view of which, various sectors call for this situation to be addressed, since of not doing it, the Democratic State of Law is compromised. From this perspective, the recent history of the country and human rights, the narratives and exercises of the subject are reviewed as an object of study, seen from the mobilization and incidence and the State itself.
\end{abstract}

Keywords: Transitional Justice, Democracy, Human Rights, Recent political history of Mexico

\footnotetext{
*Posdoctorante en el Doctorado en Ciencia Política de la Universidad de Guadalajara (UdeG). Doctora en Estudios Latinoamericanos por la UNAM. Maestra en Derechos Humanos y Democracia por FLACSO México. Licenciada en Historia por la UdeG. Experiencia internacional en contextos de conflicto y construcción de la paz. Investigación, formación y publicaciones en: Historia reciente de Latinoamérica (particularmente Centroamérica), paz, violencia, justicia transicional, seguridad y militarización.
} 


\section{Un enfoque problematizador}

En el México actual se está viviendo una compleja situación social y política que es posible apreciar en diferentes voces que, sea desde la experiencia empírica o la construcción teórica, están trabajando en aportar reflexiones y acciones para enfrentar el contexto en relación a los derechos humanos de la historia reciente, así como un sistema de alta y persistente violencia, que se inició alrededor del 2000. El encuadre teórico y político que ha emergido es la justicia transicional, con una fuerte resonancia en nuestros días.

La justicia de transición, otra acepción del término, desde su definición más genérica, resume un conjunto de significados de alta complejidad racional y emocional, ya que involucra una gran diversidad de aspectos que insertados entre la teoría y la práctica, abordan las violaciones masivas a los derechos humanos en los procesos de cambio que provienen de situaciones sociales de violencia masiva, y que están en búsqueda de estabilización y paz; y se esfuerzan en consolidar regímenes políticos fundados en los principios democráticos, los derechos humanos y el Estado de Derecho (González, 2013, p. 3).

La justicia transicional ha llegado a México desde diferentes vías y por distintos sectores, como el académico, el social y el político, que han recurrido a las experiencias de otros contextos que apoyan el hecho de que una gestión adecuada de un pasado reciente con graves violaciones a los derechos humanos, con la confianza de que ésta contribuya al fortalecimiento de las prácticas democráticas de la sociedad y a la restauración del tejido social. Es decir, la construcción de un proceso democrático tiene mucho que ver con su conocimiento del pasado, tanto de sus contenidos como de la naturaleza de su comunicación.

La pretensión por ocultar los eventos violentos sucedidos oscurece y nubla la realidad pasada, que de todas formas persiste en diferentes partes de la memoria individual y colectiva, y es transmitida por diversos medios que dejan una marca en los imaginarios sociales que pasa y se queda por generaciones, lo cual impacta en las prácticas, valores y formas de conducta intrapersonal y colectiva, dejando latente la posibilidad de la repetición de actos deshumanizantes que conllevan finalmente a la continuación de la impunidad.

Sea como plataforma teórica, el término hace referencia a la intervención en procesos de posviolencia, o como herramienta para la promoción, protección y defensa de los derechos humanos en línea del tiempo, la justicia transicional, está colocada inseparablemente de una fuerte discusión en todos sus ángulos, ya que la naturaleza de su argumentación y racionalidad atraviesa complejos asuntos que tienen que ver con la política, la moral y aquellos rasgos subjetivos que subyacen en lo más recóndito de la concepción de humanidad, de ello se decanta que será siempre un terreno en disputa.

La apuesta de impulsar en México los principios y mecanismos de la justicia transicional es aún una discusión incipiente, ya que cada sociedad responde a sus propias características; es decir, no existen modelos homogéneos, por el contrario, las lecciones aprendidas revelan insistentemente que cada proceso es extremadamente singular.

A partir de las consideraciones anteriores, este trabajo plantea el siguiente supuesto: la emergencia de la justicia transicional en México es consecuencia de un contexto actual de alta y persistente violencia, que se suma a un legado de violaciones a los derechos humanos en la historia reciente del país, -lo que ha provocado una inquietud en todos los sectores de la sociedad-, agravado por una impunidad continuada, lo que implica que se está ante un escenario urgente de atender, a través de mecanismos, acciones y políticas que atiendan tanto las causas como las consecuencias de esta realidad. Dentro de estas acciones, la justicia transicional hace énfasis en: la necesidad de gestionar el pasado, tanto para la restauración del tejido social, como para la consolidación de un Estado Democrático de Derecho, por lo cual, este paradigma ha sido cultivado desde diversos actores.

Bajo esta perspectiva se argumenta que, los trabajos en el campo de la justicia transicional construyen una relación intrínseca entre la Historia y la Política, ya que al gestionar el pasado violento y de violaciones a los derechos humanos, se está enfrentando una discusión política en dimensión de temporalidad, lo que da como resultado la necesidad de revisar, cambiar o fortalecer las narrativas historiográficas del periodo, por una parte; y por otra, genera la impresión de que si se gestiona adecuadamente ese pasado, se está en condiciones de instalar un proceso de consolidación democrática. Este ejercicio reivindica los derechos humanos en su integralidad y convoca al Estado de Derecho, en tanto abre caminos para abatir la impunidad.

Así, la justicia transicional en México viene a ser una oportunidad para revisitar ese pasado reciente desde la perspectiva de un enfoque de derechos, para reconfigurar la historiografía del periodo, si es que la evidencia así lo demanda. 


\section{El paradigma de la justicia transicional}

La narrativa de la justicia transicional ha ido evolucionando con el tiempo, enriqueciéndose y moldeado de acuerdo a las reflexiones teóricas y experiencias en que ha sido utilizada, de tal forma que se ha establecido ya como un referente teórico:

La 'justicia transicional'-este es el nombre esperanzador que hemos comenzado a utilizar para describir lo que es en realidad una muy amplia gama de problemas diferentes- se refiere a los retos y oportunidades especiales para lograr la justicia en sociedades que intentan una transición hacia un orden más pacífico y democrático (Pensky, 2006, p. 113).

\section{Valencia por su parte explica que:}

Bajo este neologismo tomado de la lengua inglesa se conoce hoy todo el conjunto de teorías y prácticas derivadas de los procesos políticos por medio de los cuales las sociedades tratan de ajustar cuentas con un pasado de atrocidad e impunidad, y hacen justicia a las víctimas de dictaduras, guerras civiles y otras crisis de amplio espectro o larga duración, con el propósito de avanzar o retornar a la normalidad democrática (Valencia, 2007, p. 1).

Ardilla (2008, p. 4) ha precisado los cuatro principios básicos que al día de hoy se identifican como las dimensiones que integran la justicia transicional:

1. La satisfacción del derecho a la justicia

2. La satisfacción del derecho a la verdad

3. La satisfacción del derecho a la reparación de las víctimas

4. La adopción de reformas institucionales y otras garantías de no repetición

La movilidad del paradigma, ya sea como objeto de estudio o para intervenciones posviolencia, ha suscitado diversas reflexiones en torno a sus aprendizajes. Algunos estudios pilares para su análisis son: After Oppression: Transitional Justice in Latin America and Eastern Europe dessarrollado por Popovsky y Serrano (2012) y La justicia transicional en perspectiva comparada: Centroamérica y México de Orduña y otros (2018).

Una conclusión general de estos estudios es que todos los procesos son muy distintos entre sí, y que la atención a las particularidades únicas y específicas de cada contexto han dado mejores resultados. Es decir, que si bien hay principios y mecanismos comunes entre las experiencias que han transitado procesos de justicia transicional, la naturaleza de cada uno es fundamentalmente singular ya que responde a sus propias características naturales, económicas, culturales, sociales y políticas.

\section{La historia reciente de México y los Derechos Humanos \\ Apuntes de la historia política reciente}

La crónica presidencial mexicana da un panorama rápido de los cambios políticos de las últimas décadas: un partido que gobernó durante 70 años; y del 2000 a la fecha, distintos cambios de partidos gobernantes.

En una esperada alternancia democrática, llegó al poder el Partido de Acción Nacional (PAN), quien gobernó por dos periodos consecutivos, con Vicente Fox Quesada (2000-2006) y Felipe Calderón Hinojosa (2006-2012). El regreso del PRI se dio con Enrique Peña Nieto (2012-2018), en un giro que no ha merecido una narrativa de cambio importante de régimen. Finalmente, Andrés Manuel López Obrador (2018) por el partido MORENA llegó al poder y de acuerdo a diversos analistas, puede representar un cambio de rumbo, que aún está por definirse.

El historiador Meyer planteaba en 1976 que en el México contemporáneo los procesos de lucha abierta entre los grupos, tan característicos del sigo XIX y de las tres décadas posteriores a la Revolución mexicana de 1910, tuvieron una importancia menor que los esfuerzos de coordinación y conciliación entre intereses; por lo que el problema político y social más importante de ese periodo radicaba en la contradicción entre las estructuras sociales en que descansaba el Estado, y los fundamentos de legitimidad del régimen. Argumentaba que, el desarrollo social fue posible dentro de un ambiente de gran estabilidad política, debido en buena medida al control oficial sobre las demandas de los sectores que hubieron de sostener el rápido proceso de capitalización: obreros y campesinos.

Este control se logró a través del partido oficial (Partido Revolucionario Institucional -PRI) en el caso de sectores organizados, e impidiendo por diversos medios la acción de fuerzas políticas independientes entre éstos o entre los vastos grupos desorganizados y marginales del campo y la ciudad (Meyer, 1976, pp. 1352-1353).

Morales también coincide en que la estabilidad del régimen presidencialista fue sostenida a partir de 1946 gracias a la maquinaria priísta en combinación con un sistemático sometimiento de los grandes sindicatos y la exclusión de las disidencias al interior del aparato gubernamental, todo esto siempre con el objetivo del crecimiento económico: Estas acciones garantizaron la anhelada estabilidad social del régimen (Morales, 2018 pp. 316). "Al comienzo de 1970, el presidencialismo de sistema de partido casi único había sobrevivido a muchas disidencias, rupturas internas, guerrillas rurales, magnicidios y confrontaciones diversas con la sociedad civil'(Morales, 2018, pp. 316-317). 


\begin{tabular}{llll}
\hline$-\begin{array}{l}\text { Adolfo Ruiz Cortines } \\
(1952-1958)\end{array}$ & $\bullet$ & $\begin{array}{l}\text { Luis Echeverría Álvarez } \\
(1970-1976)\end{array}$ & $\bullet \begin{array}{l}\text { Carlos Salinas de Gortari } \\
(1988-1994)\end{array}$ \\
Adolfo López Mateos & $\bullet \begin{array}{l}\text { José López Portillo } \\
(1976-1982)\end{array}$ & $\bullet \begin{array}{l}\text { Ernesto Zedillo Ponce de } \\
\text { León } \\
(1958-1964)\end{array}$ & $\begin{array}{l}\text { Miguel de la Madrid } \\
\text { Hurtado } \\
(1982-1988)\end{array}$ \\
$\begin{array}{l}\text { Gustavo Diaz Ordaz } \\
(1964-1970)\end{array}$ & $\bullet$ & \\
\hline
\end{tabular}

Autoria propia. Cuadro que reseña la notable duración en el poder del Partido Revolucionario Institucional (PRI) en México. Vista a partir de la mitad del siglo pasado.

Okuneva, con una mirada externa, publicaba en 2010 desde una revista en Moscú: El glorioso Bicentenario: algunas reflexiones acerca de las particularidades de la historia mexicana, artículo en el cual analiza que, concluido el mandato de Lázaro Cárdenas, se inició un periodo que, pese a los problemas persistentes, las contradicciones, la lucha política, los pasos que en ocasiones se dieron atrás, se puede hablar en conjunto de un periodo de reformas moderadas y desarrollo progresivo estable con orientación social (Okuneva, 2010, p. 12). A su vez aclara que:

Es bastante obvio que todo lo dicho de ningún modo contradice el hecho de que la historia mexicana de la segunda mitad del siglo XX y de los inicios del siglo XXI se caracteriza por la aguda lucha política; la historia actual de México pone de relieve la búsqueda de las vías del cambio social, las relaciones bastante contradictorias entre la sociedad civil y el Estado; en los últimos años somos testigos de la verdadera guerra entre el gobierno y las comunidades criminales, incluso el narcotráfico (Okuneva, 2010, p. 13).

Estas narrativas sobre la estabilidad política nacional en la segunda mitad del siglo XX comenzaron, de alguna manera, a ser modificadas por la irrupción de los acontecimientos de la década del sesenta. El contexto de este periodo se enmarca en una intensa dinámica global caracterizada por fuertes movimientos que luchaban por el cambio económico, social, político y cultural. Las expresiones de lucha recorrieron diversos formatos, temporalidades y contenidos, así como distintas formas de representaciones, pero tenían en común la reivindicación por el cambio hacia una sociedad más justa y humanizada.

Para México los sesenta y las décadas inmediatas fueron años clave, ya que a las diversas manifestaciones de lucha se siguieron crisis sociales y políticas, mismas que tuvieron políticas represivas por parte del Estado. Estos hechos inauguraron un nuevo momento para la historia nacional. Particularmente se encuentran, las narrativas relativas a las violaciones de los derechos humanos a raíz de los procesos que culminaron con la masacre de Tlatelolco en 1968, con la masacre del Jueves de Corpus "El Halconazo" en 1971, y la estrategia contrainsurgente de la denominada "guerra sucia". Estos eventos y las manifestaciones que se les circunscribieron, fueron reprimidos y silenciados; no obstante, comenzaron a configurar un nuevo registro histórico desde distintos actores individuales y colectivos, que hablaba del fin de la estabilidad política y de los efectos que traería la estrategia represiva, como impulsora de nuevos movimientos.

La idea de la larga estabilidad también fue analizada desde la perspectiva comparada, Treviño, citando el texto de Alan Knight respecto a las "peculiaridades de la historia mexicana", explica que los argumentos centrales del historiador fueron que en México, a diferencia de lo que ocurría en Centro y Sudamérica, el régimen autoritario del PRI mantuvo durante más de 60 años la "paz social", con la sola excepción de la "guerra sucia", que en todo caso fue un "pleito menor comparado con las barbaridades" que se cometían en otros países de la región. Treviño concluye que esta idea, acerca de que el México autoritario era estable, pacífico y poco violento, sería ampliamente compartida por la mayoría de quienes desde la academia estudiaban al país y a su régimen político (Treviño, 2018, pp. 61-62).

A partir del 2000 con la llegada de Fox a la presidencia se fue instalando un nuevo discurso sobre la transición democrática en México, que colaboró con el marco de la aparición de la justicia transicionalen el país. Esta afirmación se basa en que, el canon de este paradigma se plantea que es aplicable a sociedades en tránsito, ya sea de conflictos a la paz, o del autoritarismo a la democracia, con lo cual las dudas y las disputas en torno al tema, han venido a ganar terreno.

Sobre la transición, Cervantes argumenta que estudios politológicos han puesto en evidencia que si bien se han logrado avances en materia electoral, el país no puede considerarse verdaderamente democrático, 
Hoy en día suele abusarse del paradigma de la transición a la democracia con el arribo del Partido Acción Nacional al poder federal, pero lo cierto es que en realidad se trató de una democratización parcial que, pese a los avances en materia electoral que se efectuaron (principalmente en la década de los noventa), no ha logrado consolidarse (Cervantes, 2016, p. 1).

El autor concluye entre otras cosas que si se concibe el proceso de democratización en un sentido más amplio y consideramos los desafíos que actualmente enfrenta el Estado Mexicano en materia de derechos humanos y participación ciudadana, claro está que poco se ha avanzado y que México dista mucho de ser considerado un Estado verdaderamente democrático, pues la democracia no se reduce a la participación de la ciudadanía en la elección de sus representantes. Bajo esta perspectiva, es evidente que la afirmación de los llamados "transitólogos", quienes afirman que en el año 2000 México logró transitar a la democracia, resulta ser ambigua y reduccionista (Cervantes, 2016, p. 11).

\section{La historia reciente y los derechos humanos}

Un análisis interpretativo de violaciones a los derechos humanos a lo largo del tiempo en la historia reciente de México, es la construcción de ciclos elaborada por Ceja, planteando el punto de inflexión en 1968, una etapa previa y cuatro ciclos post-Tlatelolco. Para el autor, el pasado "reciente" en el caso mexicano se remite a la década de los años sesenta del siglo pasado, "la brutal respuesta del gobierno federal al movimiento estudiantil de 1968, específicamente lo sucedido el 2 de octubre en Tlatelolco, que constituye un punto de inflexión en la política represiva gubernamental" (Ceja, Comunicación personal, octubre 31 del 2019).

\title{
Cuadro 2
}

Violaciones a los Derechos Humanos Pre-Tlatelolco

- Represión en contra del $\begin{aligned} & \text { Represión en contra de los } \\ & \text { Movimiento Ferrocarrilero } \\ & (1959)\end{aligned}$
médicos del ISSSTE (1964)

- Asesinato del dirigente campesino Rubén Jaramillo junto a su familia (1962)
Masacre de productores campesinos copreros en Guerrero (1967) estudiantes de 1 a Universidad San Nicolás de Hidalgo, Morelia, y de la Universidad de Sonora (1966)

- Represión en contra de los integrantes de la Asociación Civica Guerrerense (a partir de 1960)

\begin{abstract}
Autoria propia. Cuadro hecho a partir de los detalles que me compartió Ceja en la comunicación que sostuvimos. (Ceja, Comunicación personal, octubre 31 del 2019)
\end{abstract}

Los hechos que siguieron a Tlatelolco se narran a continuación:

El primer ciclo iniciaría con la matanza y represión del 10 de junio de 1971, ocurrida en la Ciudad de México en contra de una manifestación estudiantil pacífica. Y continúa la ola de terror estatal (la guerra sucia) desatada, entre otros aparatos represivos, por la Dirección Federal de Seguridad y la Brigada Blanca en contra de los integrantes y simpatizantes de los grupos guerrilleros rurales y urbanos. Diversos organismos pro derechos humanos, como académicos, estiman la existencia de más de mil detenidos-desaparecidos en todo el país como parte de los saldos de la guerra sucia.

En un segundo ciclo post Tlatelolco -a partir del gobierno de Miguel de la Madrid Hurtado, 19821988- habrá que recordar los asesinatos en contra de periodistas, militantes y simpatizantes del Partido de la Revolución Democrática; la masacre de campesinos en Coyuca de Benítez, Guerrero; la de Acteal, en Chiapas, y la de El Charco, Guerrero, las tres cometidas durante el gobierno de Ernesto Zedillo Ponce de
León (1994-2000).

Un tercer ciclo post Tlatelolco, inicia con la alternancia política panista (con el triunfo electoral de Vicente Fox Quesada) inaugurado a partir de diciembre de 2000. Durante su gobierno se efectúan los siguientes actos de represión: 28 de mayo de 2004 en Guadalajara en contra de una manifestación pacífica -infiltrada por provocadores- desarrollada en el marco de la III Cumbre Unión Europea-América Latina y el Caribe; en contra de los mineros de Sicartsa en Lázaro Cárdenas, Michoacán (abril 2006); la represión en San Salvador Atenco, estado de México, en contra de los integrantes del Frente de Pueblos en Defensa de la Tierra (mayo de 2006); y, entre otras graves violaciones a los derechos humanos, la dirigida en contra de integrantes de la Asamblea Popular de los Pueblos de Oaxaca (2006).

Un cuarto ciclo, ya con connotaciones expansivas, masivas, sistemáticas y, en no pocos casos, indiscriminada, en contra de los derechos humanos, inicia con la presidencia ilegítima del panista Felipe Calderón Hinojosa (2006-2012) y continúa a lo largo del sexe- 
nio del priista Enrique Peña Nieto. La llamada guerra contra el narco' y el enfrentamiento entre los bandos inter-estatales e inter-narcos desataron la violación en contra de los derechos humanos -y los niveles de crueldad-como nunca antes en la historia de México; por lo menos desde la llamada conquista española. Se trata de millones de víctimas directas e indirectas donde el Estado mexicano -sea por acción u omisión- tiene una fuerte responsabilidad. Tal cual ha sido señalado por múltiples organismos nacionales e internacionales de derechos humanos, como por las organizaciones familiares de víctimas. Es durante el sexenio de Peña Nieto en que ocurren los actos de violencia estatal en Nochixtlán (Oaxaca), Tlatlaya (Estado de México), Apatzingán y Tanhuato (Michoacán). También cuando ocurrieron los actos de violencia narco-estatal, entre ellos la desaparición forzada de los 43 jóvenes estudiantes de la Escuela Normal Rural Raúl Isidro Burgos de Ayotzinapa; hechos ocurridos en Iguala, Guerrero (Ceja, Comunicación personal, octubre 31 del 2019).

La evolución presentada por este autor aporta tres contribuciones:

1. Una lectura crítica de la historia reciente desde una perspectiva de Derechos

2. Una base para el debate en las narrativas historiográficas del periodo

3. Un registro de eventos organizado en el tiempo, para un análisis político de la transición a la democracia en México

\section{Casos paradigmáticos para la justicia transicional}

Las experiencias en distintos contextos y sociedades a lo largo del mundo del siglo XX a la fecha, señalan como un punto de partida clave para la justicia transicional, la identificación de casos graves de violaciones a los derechos humanos. Sin embargo, esta selección de casos es un tema sumamente complejo, ya que involucran aspectos de muy distinta índole, objetivos y subjetivos; porque involucran poderes de distinto orden, a la vez de que dependen del interés, compromiso y cumplimiento de obligaciones ante víctimas y sobrevivientes, de los distintos sectores de la sociedad.

Una revisión a la evolución de la justicia transicional permite considerar que sus casos-objeto tienen características comunes, entre las que encontramos al menos cuatro fundamentales: son masivos en su mayoría; son paradigmáticos por su complejidad; comprometen el régimen democrático y la lucha contra la impunidad; y tienen un fuerte carácter simbólico. Con el propósito de visibilizar una lista mínima de casos para la historia reciente de México, se consolidó la siguiente guía, a partir de fuentes consultadas y de las entrevistas realizadas: de las entrevistas realizadas:

- $\quad$ 1968. Ciudad de México: Masacre de Tlatelol-

co

- $\quad$ 1971. Ciudad de México: La Masacre del Jueves de Corpus "El Halconazo"

- 1960-1970. Estado de Guerrero

- $\quad$ 1993-Estado de Chihuahua: Feminicidios en Juárez

- $\quad$ 1995. Estado de Guerrero: Masacre de Aguas Blancas

- $\quad$ 1997. Estado de Chiapas: La Matanza de Acteal

- 2001. Estado de Chihuahua: Caso "Campo Algodonero"

- 2006. Estado de México: La masacre de Atenco

- 2006. Estado de Oaxaca: Conflicto social. Asamblea Popular de los Pueblos de Oaxaca (APPO)

- 2009. Estado de Sonora: Incendio de la Guardería $\mathrm{ABC}$

- 2010. Estado de Tamaulipas: Primera masacre de San Fernando

- 2011. Estado de Tamaulipas: Segunda masacre de San Fernando

- 2012. Estado de Nuevo León: Masacre de migrantes en Cadereyta

- 2014. Estado de México: Matanza de Tlatlaya

- 2014. Estado de Guerrero: Desaparición Forzada de Iguala, Caso de los 43 normalistas de Ayotzinapa

- 2015. Estado de Michoacán: Masacre de Tanhuato

- 2016. Estado de Oaxaca: Enfrentamiento de Nochixtlán

La construcción de esta lista puede contribuir al menos en los siguientes aspectos: contar con una guía de casos que no pueden dejar de ser nombrados en cualquier ejercicio de justicia transicional en el México de la historia reciente; contar con un panorama general que proporcione una noción de conjunto de tiempos y espacios, a partir de considerar, ritmos, periodicidades, continuidades, contigüidades e inflexiones en relación al contexto político; la posibilidad de establecer un parámetro de seguimiento, en un sentido observatorio, que contemple al menos: el comportamiento del Estado, la situación de víctimas y sobrevivientes; el acompañamiento de diversos actores como familiares y sociedad civil; y el registro teórico-práctico para la intervención en situaciones concretas, así como objeto de estudio en la academia.

\section{Justicia transicional en México desde el rol de los actores}

Explorando las narrativas sobre justicia transicional en México en el momento actual, podemos agruparlas en tres tipos de procesos: en la agenda de conocimiento, en la agenda social y en la agenda de Estado, que presentan de alguna manera interconexiones y complementariedades. 


\section{Como objeto de estudio: en la agenda de conocimiento}

En el marco de los espacios para la construcción de conocimiento, se pueden observar dos aspectos; por una parte, los trabajos recientes; y por la otra, los trabajos que se integran desde una perspectiva interdisciplinaria, donde hay una lógica de análisis integrador entre dimensiones políticas, históricas y del ámbito del derecho. En orden cronológico destacan cuatro materiales: un artículo en 2017, y tres publicaciones al año siguiente: un artículo, un libro y una publicación donde colaboraron la academia y una institución oficial.

- 2017. Artículo "La línea del horizonte transicional y los problemas de procesar crímenes de lesa humanidad en México: un análisis de sus documentos clave” de Jesús Pérez Caballero

Aquí el autor discute los problemas que tiene el país para tratar penalmente algunos de sus crímenes más graves, -situación que no tiene precedentes en el resto de la región-, a partir de comparar otros procesos de la región latinoamericana. Y señala que:

Por lo tanto, México, aparentemente, no ha vivido en las últimas décadas una situación excepcional similar a una guerra y, teóricamente, las instituciones podrían procesar por sí mismas los delitos más graves. Sin embargo, en la práctica, sectores del Estado sí han promovido violaciones de derechos humanos que, en algunos casos, se argumenta que podrían alcanzar el umbral de crímenes internacionales diferentes a los vinculados a una guerra, a saber, genocidio o crímenes de lesa humanidad, sea ello antes de la transición democrática simbolizada en la victoria del PAN en las elecciones federales del año 2000 (Dutrénit y Varela, 2010, pp.85-86) o incluso, según algunas fuentes, con posterioridad (Pérez, 2017, pp. 63-64).

Y entre otras problemáticas que se deberán enfrentar, explica el autor, están:

la dificultad de aplicar la costumbre internacional directamente sin una tipificación nacional, la necesidad de probar un patrón desde la perspectiva del DPI (Derecho Penal Internacional), la fragmentación en la condición de víctima o los nuevos tipos de continuidad de las estructuras contrainsurgentes, entre otras cuestiones penales materiales y formales objeto de este artículo. Tales retos obligan a utilizar conceptos novedosos y enfoques arriesgados en el ámbito procesal penal (Pérez, 2017, p.64).

Temas en los cuales plantea nuevas posibilidades de cómo abordarlos.

- 2018. Artículo "Las deudas de la verdad en México ante el discurso de justicia transicional" de Sarahí Salvatierra, Andrés M. Díaz y José Knippen

Los autores describen el panorama actual de la violencia polifacética en México, caracterizando entre otros elementos: un cerco que la delincuencia organizada ha impuesto territorialmente en varias zonas del país; una violencia estatal "es decir, marcos normativos que no cumplen los estándares de protección de los derechos humanos, así como fuerzas armadas o cuerpos policiacos que cometen múltiples violaciones de los derechos humanos" (Salvatierra y otros, 2018, p.114); y la violencia social,

donde la víctima directa es la sociedad mexicana, que no cuenta con mecanismos eficientes de participación que le permitan tener un rol activo en la construcción de políticas de seguridad humana y reparación a víctimas, así como para monitorear la actuación efectiva del Estado (Salvatierra y otros, 2018, p. 114).

Ante esta situación, el Estado prometió responder a las demandas de investigación y justicia de los hechos del pasado. El aporte de los autores está en la revisión de los momentos claves en que se hicieron promesas de justicia transicional:

la guerra sucia y la Fiscalía Especial para Movimientos Sociales y Políticos del Pasado (FEMOSPP), después con la "guerra contra el narcotráfico", declarada por el presidente Felipe Calderón, del PAN, al inicio de su sexenio en 2006 y, finalmente, con la Ley General de Víctimas aprobada en 2013 (Salvatierra y otros, 2018, p. 115).

Todos concluyen en que está ausente un enfoque crítico, manifiesto en la carencia de garantía de verdad para violaciones graves de derechos humanos.

- 2018. Libro "La justicia transicional en perspectiva comparada: Centroamérica y México", coordinado por Eva Leticia Orduña, Ralph Sprenkels y Jorge Juárez.

Este texto explora la justicia transicional en El Salvador, Guatemala y México, con dos capítulos por cada país, y un capítulo introductorio que da pautas para un análisis comparativo. Los que abordan la situación nacional son: "Ante las Justicias Transicionales de México" de Javier Treviño Rangel; "Los trabajos y los días, la memoria y el olvido. Afanes y tropiezos de la justicia transicional en México” de Francisco Ramírez Treviño. 
Entre otros temas, Treviño "cuestiona la creencia, compartida por diversos observadores como Alan Knight, de que lo que existió en México fue 'un pleito menor comparado con las barbaridades' de otros países" (Orduña y otros, 2018, p.19); y aporta reflexiones en torno a la FEMOSPP y las Comisiones de la Verdad de los estados de Guerrero y de Oaxaca. Por su parte, Ramírez, entre otros contenidos, aborda también "los cánones que desde el derecho internacional se han establecido en relación con la justicia transicional, así como la problemática que se ha suscitado respecto a la tensión entre la paz y la justicia” (Orduña y otros, 2018, 19), y analiza la FEMOSPP y la Comisión de la Verdad del estado de Guerrero.

- 2018. Publicación "Estudio para elaborar una propuesta de política pública en materia de justicia transicional en México” del Centro de Investigación y Docencia Económicas y la Comisión Nacional de Derechos Humanos (CIDE) y la Comisión Nacional de Derechos Humanos (CNDH)

El documento parte de la explicación de la situación del país

México vive desde hace varios años un fenómeno de violencia a gran escala. Las víctimas suman miles. Esta grave situación y sus consecuencias no han podido ser atendidas desde las instituciones y mecanismos ordinarios de justicia. Se trata de un problema de violaciones a derechos humanos, delitos que no han sido sancionados, impunidad por hechos no esclarecidos, víctimas que no han sido identificadas, atendidas y reparadas, así como de instituciones que carecen de capacidades para garantizar que los hechos no se repitan (CIDE-CNDH, 2018, p. 19).

Se explica en el texto que, ante situaciones similares, otros países han implementado una política de justicia transicional, y que la coyuntura en México con el cambio de administración federal ha abierto una discusión pública sobre el tema, por lo cual el documento ofrece insumos que aportar a la discusión para la toma de decisiones en materia de reformas legales, diseño institucional y construcción de una política pública de justicia transicional.

Aclara que la $\mathrm{CNDH}$ en atención a los graves problemas descritos, en relación al fenómeno de la violencia, así como de su vinculación con otros problemas estructurales como la corrupción, la impunidad, la pobreza, la desigualdad social y el débil Estado de derecho, (además de las repercusiones que tiene esto en la garantía de los derechos humanos de las personas, en particular de las víctimas), solicitó al CIDE un estudio para elaborar esta propuesta, que ofrece:

un marco conceptual, experiencias comparadas relevantes para el caso mexicano, así como propuestas concretas, que pueden servir de insumo para elaborar políticas públicas en materia de JT que resulten acordes con el marco constitucional, convencional y legal en materia de derechos humanos (CIDE-CNDH, 2018, p. 20).

\section{Desde la movilización e incidencia: en la agenda social}

Al margen de múltiples, comprometidas, complejas y largas acciones de actores individuales y colectivos que han luchado por la gestión del pasado ante violaciones a los derechos humanos en la historia reciente, hoy se cuenta con dos procesos de reciente creación; presentados en 2019, que están reuniendo a diversos actores y sectores que se enfocan en la demanda de procesos y mecanismos relativos a la justicia transicional. El primero es un proceso participativo y multisectorial que culminó con una propuesta de política pública; y el segundo, tiene que ver con la creación de un tanque de pensamiento.

2019. "Propuesta ciudadana para la construcción de una política sobre verdad, justicia y reparación. A las víctimas de la violencia y de las violaciones a los derechos humanos"

- 2019. "Propuesta ciudadana para la construcción de una política sobre verdad, justicia y reparación. A las víctimas de la violencia y de las violaciones a los derechos humanos"

Este documento cuenta con dos contenidos relevantes: el contexto que presenta sobre la situación de México -de creación colectiva-, y la exposición de planteamientos concretos para una política pública sobre verdad, justicia y reparación.

Sobre lo primero, hace referencia a la difícil situación que el país enfrenta:

La extrema violencia e inseguridad, así como los altos índices de impunidad y corrupción en la República mexicana, exigen la aplicación de una política integral de verdad, justicia y reparación a las víctimas de la violencia y de las violaciones a los derechos humanos que sea efectiva y genere resultados a corto, mediano y largo plazo. El número creciente de víctimas, así lo demanda (CMDPDH, 2019, p. 11). 
Como antecedente en el documento se explica que:

organizaciones de la sociedad civil, defensores de los derechos humanos, estudiosos e investigadores de la Academia y, muy destacadamente, colectivos de familiares y víctimas del conflicto han contribuido con ideas, estrategias y recomendaciones para generar mecanismos tendientes al reconocimiento de las violaciones a los derechos humanos y a la reparación integral del daño, así como al combate a la impunidad (CMDPDH, 2019, p.11).

Pero el conflicto ha evolucionado y se agrava, "pues las estrategias que se han seguido para contraatacarlo han sido erróneas, desarticuladas o limitadas".

Sobre el proceso, se señala que fue complejo y que inicio años atrás cuando como sociedad civil comenzaron a exigir el alto a la violencia y el esclarecimiento de los miles de crímenes cometidos con motivo de la estrategia fallida de seguridad iniciada en 2006, y previo a ello,

mediante acciones que intentaban alcanzar la justicia a las víctimas de crímenes de Estado de 1968, 1971 y de la llamada "guerra sucia" de los años setenta, o bien promocionando el establecimiento de un mecanismo internacional para hacer frente a la impunidad (CMDPDH, 2019, p. 12).

\section{Posteriormente,}

durante la campaña presidencial, el 8 de mayo cuatro de los aspirantes a la presidencia de la República, entre ellos Andrés Manuel López Obrador, se presentaron a una convocatoria formulada desde la sociedad civil 'Diálogos por la Paz y Justicia. El ahora presidente de la República, en dicho evento, reafirmó su compromiso por la búsqueda de la verdad y la erradicación de la impunidad. Dijo estar de acuerdo y abierto 'a que organizaciones internacionales que trabajan para evitar la impunidad puedan intervenir en el país y puedan perseguir delitos' (CMDPDH, 2019, p. 12).

El proceso se consolidó el 14 de septiembre a partir del "Segundo diálogo por la paz, la verdad y la justicia", cuando "cientos de organizaciones de sociedad civil y víctimas de todo el país exigieron al gobierno electo, allí presente, que se iniciaran mesas para delinear la agenda de verdad, justicia y reparación con la participación y responsabilidad del gobierno" (CMDPDH, 2019, p. 12). Las mesas trabajaron alrededor de tres meses.

Los planteamientos claves que desarrolla el documento son cuatro:

1. La creación de un Mecanismo Internacional contra la Impunidad en México (MICM)

2. La creación de una Comisión de la Verdad y de la Memoria Histórica (CVMH):

que ayude a romper el silencio y, en consecuencia, la impunidad sobre las graves violaciones a los derechos humanos que se han vivido en el país entre el primero de diciembre de 2006 al presente, y entre el primero de enero de 1965 y el 30 de noviembre de 2006 (CMDPDH, 2019, pp. 12-13).

3. La creación de un modelo de reparación extraordinario, que sea integral y garantice la existencia de mecanismos efectivos de reparación a las víctimas de violaciones graves de derechos humanos en el país

4. La participación de las víctimas en ese proceso

\section{- 2019. "Un espacio de reflexión (Think Tank) en Justicia Transicional para México"}

Mariclaire Acosta explica que esta instancia:

se conformó para construir un espacio de análisis multidisciplinario integrado con personas expertas en justicia transicional para el caso mexicano en las áreas de trabajo: investigación, memoria y verdad, incidencia, capacitación, divulgación y asistencia técnica. El blog es un espacio de opinión e incidencia sobre temas relacionados con JT (Acosta, 2019, p.1).

Respecto a las condiciones del país señala que:

México enfrenta una crisis de violencia e impunidad sin precedentes, resultado de la debilidad y captura de sus instituciones, especialmente las de seguridad y justicia, que han sido incapaces en las últimas dos décadas de afrontar los numerosos e intensos conflictos entre organizaciones criminales y de éstas con las autoridades del Estado. Ante este panorama, el presidente Andrés Manuel López Obrador presentó durante su campaña un discurso de pacificación y reconciliación en el que destacaron las figuras de amnistía, perdón y desmovilización como elementos centrales de su política de seguridad. Algunos de sus colaboradores interpretaron estas figuras como componentes de una propuesta de justicia transicional (JT) para hacer frente al fenómeno descrito (Acosta, 2019, p. 2).

\section{La autora expone que es fundamental contar con}

un espacio dinámico y multidisciplinario con personas expertas y especializadas en JT para el caso mexicano y, de manera transversal, que tenga experiencia en el trabajo en campo con víctimas, género y reparación a víctimas, así como experiencia en la función pública, conocimiento internacional y capacidad de articulación e interlocución (Acosta, 2019, p. 3).

Plantea que se requiere de un Think Tank que sirva de puente con el gobierno, la academia, organizaciones de derechos humanos y víctimas, tanto de México como del extranjero. 


\section{Para la gestión pública: en la agenda de Estado}

La agenda de justicia transicional en México cuenta con tres experiencias desde la acción del Estado en la historia reciente, y diversas acciones del actual gobierno de López Obrador. Dentro de las primeras se cuenta con la FEMOSPP en 2002, la Comisión de la Verdad de Guerrero en 2012, y la Comisión de la Verdad de Oaxaca en 2013.

\section{- 2002. Fiscalía Especial para Movimientos Sociales y Políticos del Pasado}

Las labores de esta fiscalía quedaron reseñadas en el "Informe Histórico" cuyo borrador se publicó en la página Web del National Security Archive el 26 de febrero del 2006, donde se indica:

Este documento es el resultado de cuatro años de trabajo por parte de la oficina del Dr. Ignacio Carrillo Prieto, Fiscal Especial para Movimientos Sociales y Políticos del Pasado (FEMOSPP). Este organismo fue promovido por el presidente Vicente Fox para investigar crímenes en contra de los derechos humanos. Los crímenes detallados en dicho informe fueron cometidos durante las administraciones de Gustavo Díaz Ordaz (1964-1970), Luis Echeverría Álvarez (1970-1976) y José López Portillo (1976-1982). Durante esos sexenios, cientos de ciudadanos mexicanos - tanto civiles inocentes como militantes armados-fueron asesinados o "desaparecidos" por fuerzas militares y de seguridad. Miles más fueron torturados, ilegalmente detenidos, o sujetos a hostigamiento y vigilancia por parte de las autoridades" (NSA, 2006, p. 1).

Respecto al cierre de la institución, Méndez escribía en 2007:

La Fiscalía Especial para Movimientos Sociales y Políticos del Pasado (FEMOSPP) llega hoy a su fin sin haber conseguido una sola sentencia condenatoria por delitos cometidos durante las matanzas del 2 de octubre de 1968, 10 de junio de 1971 o la llamada guerra sucia, objetivo principal de su creación en el sexenio foxista. El Diario Oficial de la Federación publicó ayer el acuerdo por el cual la Procuraduría General de la República (PGR) determinó en noviembre pasado disolver la fiscalía, que el jurista Ignacio Carrillo Prieto encabezó desde 2002 (Méndez, 2007, p. 1).

Méndez señala que el logro más importante fue

conseguir orden de aprehensión y auto de sujeción a proceso contra el ex presidente Luis Echeverría Álvarez, a quien sin embargo no consiguió ver tras las rejas, pues obtuvo el beneficio de la prisión preventiva domiciliaria establecida en el artículo 55 del Código Penal Federal (Méndez, 2007, p. 5).

Entre las averiguaciones previas que dejó pendiente la FEMOSPP: la relativa al caso Aguas Blancas; el asesinato de más de 600 perredistas, la cual se inició a partir de una denuncia presentada en julio de 2002 por Cuauhtémoc Cárdenas, María Eugenia López Brun, Amalia García, Javier Hidalgo y los familiares de Francisco Javier Ovando y Román Gil Heráldez, asesinados en vísperas de la elección presidencial de 1988 (Méndez, 2007, p. 9).

\section{- 2012. Comisión de la Verdad de Guerrero}

En la Ley Número 932 por la que se crea la Comisión de la verdad (COMVERDAD) para la investigación de las violaciones a los derechos humanos durante la "guerra sucia" de los años sesenta y setentas en el estado de Guerrero, se indica que esta Comisión tiene por objeto

investigar, estudiar, analizar y aportar elementos históricos, sociales, políticos y jurídicos, para contribuir con las labores de las autoridades competentes en la investigación de violaciones a derechos humanos, y hechos probablemente constitutivos de delitos, y delitos de lesa humanidad, contra ciudadanos guerrerenses o personas radicadas o que se hayan encontrado en territorio guerrerense" (Gob. del Estado de Guerrero, Poder Legislativo, 2012, p.7).

El documento aborda entre otros temas: los antecedentes de la "guerra sucia"; los resultados de investigación sobre la violación a los derechos humanos durante ese periodo de tiempo; el registro de personas y comunidades afectadas por la violación a los derechos; la situación de familiares y sobrevivientes de desaparición forzada y tejido social; las actividades realizadas; los obstáculos que enfrentaron; propuestas de medida de reparación integral del daño y de no repetición; recomendaciones; y testimonios sobre personas desaparecidas. Las recomendaciones se agrupan en los apartados (COMVERDAD, 2014, p. 95):

1. Sobre el Derecho a la Justicia: en relación al tema de desaparición forzada

2. Medidas legislativas: relativo a tipificar la desaparición forzada

3. Medidas preventivas: que aborda entre otros aspectos, el retiro de las fuerzas armadas de las operaciones de seguridad pública, la sanción a cuerpos policiacos o de seguridad pública no pongan inmediatamente al detenido a disposición del Ministerio Público (MP), establecer en toda agencia del MP un registro de personas detenidas y crear un protocolo de inspección continua en los lugares de detención

4. Medidas de Reparación: que incluyen una serie de medidas integrales para familiares de desaparecidos y sobrevivientes 
5. Medidas administrativas o institucionales: sobre apoyo a víctimas y familiares para el proceso de trámites administrativos

6. Generales: apartado que invita a que se cumplan las recomendaciones del Grupo de Trabajo sobre las Desapariciones Forzadas e Involuntarias al Estado mexicano en su informe sobre su Misión a México. Se retiren los nombres de las personas que intervinieron en desapariciones forzadas de los lugares públicos. Se retire el nombre del ejército del lugar de honor del Congreso del Estado.

En la víspera de la presentación del informe de COMVERDAD, Petrich escribía que durante 30 meses, durante los cuales sufrieron amenazas de muerte, saqueos a sus oficinas e incluso un atentado con armas de fuego contra la vida de dos de ellos; cinco comisionados -el presidente, Enrique González Ruiz; Aquiles González, Hilda Navarrete, Pilar Noriega y Nicomedes Fuentes, este último secretario- removieron viejos archivos, hicieron excavaciones y peritajes, realizaron foros en las comunidades afectadas por los años de conflicto, para generar confianza y encontraron "que a pesar de las cuatro décadas transcurridas, en las comunidades afectadas y entre los sobrevivientes subsiste el miedo" (Petrich, 2014, p. 2).

De acuerdo a la autora, el informe documenta entre otros contenidos: 463 casos de severas violaciones al derecho humanitario, que incluyen 24 ejecuciones sumarias, 230 desapariciones forzadas, 205 casos de sobrevivientes de desaparición forzada; el trabajo de rastreo y digitalización de "centenares de expedientes depositados en el Archivo General de la Nación de los fondos de las extintas Dirección Federal de Seguridad, Dirección de Investigaciones Políticas y Sociales, así como de la Sedena y de la Procuraduría General de Justicia del Distrito Federal" (Petrich, 2014, p. 17).

Entre las novedades que aporta el informe de COMVERDAD destacan las evidencias desconocidas hasta ahora sobre los vuelos de la muerte, en los que militares arrojaron al océano Pacífico a opositores y presuntos guerrilleros en el contexto de la guerra contrainsurgente (Petrich, 2014, p. 5).

\section{- 2013. Comisión de la Verdad de Oaxaca}

De acuerdo a Miguel Concha, el Congreso de Oaxaca había aprobado la creación de una comisión de la verdad con el fin de investigar los hechos ocurridos en esa entidad, promovido por el propio gobernador y el diputado petista Flavio Sosa, indicando que esta instancia serviría para investigar violaciones a los derechos humanos y la posible comisión de delitos por parte de servidores públicos de aquella entidad contra personas vinculadas o no con el conflicto social ocurrido entre el 14 de julio del 2006 y el 16 de julio de 2007, cuando se formó la Asamblea Popular de los Pueblos de Oaxaca (APPO) que dejó un saldo de 30 asesinatos, más de una decena de desaparecidos e incuantificables detenciones arbitrarias realizadas por policías y paramilitares bajo las órdenes del gobierno de Ulises Ruiz Ortiz (Concha, 2013, p. 1).

El autor continúa explicando la delicada y compleja tarea de recabar testimonios y establecer mecanismos para que las víctimas y personas en general aporten información o pruebas sobre los hechos y que

la principal tarea de la comisión será, conjuntamente con el estado, la de tratar de conseguir una reparación integral, estableciendo al mismo tiempo garantías de no repetición. Esto es, llevar a cabo una investigación para finalmente esclarecer los hechos, y realizar un esfuerzo por procesar y castigar penal y disciplinariamente a quienes resulten responsables (Concha, 2013, p. 5).

El informe final de la comisión presentado el 3 de mayo del 2016, incluye los temas de: la tipología de víctimas; la represión; el impacto psicosocial; la impunidad; conclusiones y recomendaciones; la cronología del conflicto social; el contexto del conflicto y la caracterización del movimiento social en el Estado (Solalinde y otros, 2016, p.2). En el documento se afirma que el Estado violó los derechos humanos, entre estos: el derecho a la vida, a la integridad, el acceso a la justicia, la presunción de inocencia y acceso al debido proceso. Y que, entre las recomendaciones, destaca la dirigida a la Procuraduría General de la República para revisar las demandas penales dirigidas en contra de las administraciones federales, de Vicente Fox Quesada y Felipe Calderón Hinojosa, así como a otros funcionarios y ex funcionarios de la Federación, por su responsabilidad en los hechos del conflicto social oaxaqueño (Quadratín, 2016).

\section{Gobierno de Andrés Manuel López Obrador}

Con antecedentes en su campaña presidencial, durante el periodo de transición, y hasta el momento actual, las narrativas de justicia transicional del actual gobierno han recorrido diferentes contenidos y acciones. A pocos días del triunfo de López Obrador, el Diario La Razón reseñaba: 
Olga Sánchez Cordero, perfilada para encabezar la Secretaría de Gobernación en el próximo gobierno federal, afirmó que es crucial e inevitable empezar a hablar de justicia transicional para México, una que atienda la realidad actual del país, poniendo a las víctimas en el centro (La Razón Online, 2018, p. 4. Subrayado del autor).

Al día de hoy, el tema es visible en la agenda del gobierno federal, particularmente impulsado desde la Secretaría de Gobernación (SEGOB), ya dirigida por Sánchez Cordero. Con diferente nivel de avance y profundidad, hay instancias atendiendo o proyectadas a atender a esta problemática: la Comisión Ejecutiva de Atención a Víctimas (CEAV); la Comisión Nacional de Búsqueda de Personas (CNB); el Mecanismo Extraordinario de Identificación Forense; la Comisión para la Verdad y Acceso a la Justicia en el Caso Ayotzinapa; y la preparación de un Mecanismo de Atención Integral a Sobrevivientes de la "Guerra Sucia".

SEGOB recientemente dio a conocer el "Informe de fosas clandestinas y registro nacional de personas desaparecidas o no localizadas", Sánchez Cordero precisó que este documento comprende del 1 de diciembre de 2018 al 31 diciembre de 2019 y cuenta con el registro histórico desde 1964 a la fecha”. Las acciones de búsqueda se concentraron en 519 sitios, se identificaron 873 fosas clandestinas y se exhumaron 124 cuerpos. La titular de la CNB, Karla Q., informó que hasta el 31 de diciembre se estiman: 61 mil 637 personas desaparecidas o no localizadas, y 85 mil 396 localizadas; de las cuales 74 por ciento son hombres y el 53 por ciento tienen entre 15 y 35 años de edad (SEGOB, 2020).

Por su parte, en enero recién pasado, el subsecretario de Gobierno, Ricardo Peralta comentó que el gobierno de la cuarta transformación tiene muy claro el concepto de justicia transicional, esto en respuesta al señalamiento del Movimiento por La Paz, que encabeza el activista Javier Sicilia, en el que demandó una respuesta clara sobre el tema (Lara, 2020, p. 4).

En el trabajo de rescate de la verdad y memoria, está la información que la SEGOB ha recolectado y creado, documentos a los que se puede acceder a través de su página principal:

- “QQué es la justicia Transicional?” (SEGOB, 2019)

- Sitios de Memoria. Verdad, Memoria, Justicia y no repetición" (SEGOB, s/f), que redirecciona a un sitio con extensa información y documentación, que incluye entre otros, los siguientes títulos:

- "A 48 años del halconazo" (Documental)

o "La Herencia más dolorosa" (Documental)

o "Geografía de la Represión", con un documento que contiene los nombres de 562 personas desaparecidas de manera forzada, y un mapa interactivo con datos de sitios de fuerzas de seguridad responsables de la represión

o "Sitios de Memoria", que redirecciona a cinco enlaces más en el cual destacan dos:

- "Memorial Archivos de la Represión" que redirige a un proyecto archivístico de un acervo de 310,000 documentos oficiales cuyos originales se encuentran en el Archivo General de la Nación

- "Memorial Memoria y Verdad", que redirecciona a la lista de casos paradigmáticos con información y documentación de cada caso: Acteal, Aguas Blancas, Atenco, Apatzingán, Ayotzinapa 2011, Ayotzinapa 2014, Cadereyta, Campo Algodonero, Guardería ABC, Guerra Sucia, El Halconazo, San Fernando 2010, San Fernando 2011, Tlatelolco y Tlatlaya.

\section{Conclusiones}

\section{La mediación entre la historia y la política en la justicia transicional}

Los temas relativos a la justicia transicional se hanvuelto cada vez más complejos y alejados de una matriz unidisciplinaria. En este sentido, ha ido el esfuerzo de mediar entre la Historia y la Política en este trabajo. Se ha logrado exponer que la justicia transicional contribuye a la creación de registros historiográficos con un enfoque de derechos, y, por lo tanto, permite una mirada crítica hacia la calidad de los procesos políticos.

El ejercicio de visibilizar la historia reciente contribuye a posicionar los cuestionamientos que se hacen respecto a la transición y construcción democrática en México, a partir de considerar etapas de represión autoritaria y la ausencia de políticas estatales comprometidas en atender un legado de violaciones a los derechos humanos. Por otra parte, se abre una línea de debate en torno a los cambios y continuidades respecto a un Estado Democrático de Derecho, ya que un tema en el que coinciden todas las propuestas de una política de justicia transicional para el país, coincide en la urgencia de la lucha contra la impunidad. 


\section{La justicia transicional: un ejercicio hacia la reconfiguración historiográfica}

Uno de los temas en disputa que es el campo de ejercicio y acción de la justicia transicional es la inmediata revisión del pasado, lo cual conlleva la dificultad de reescribir o cambiar, la historia que ya se tenía conocida y contada a través de generaciones.

En el caso de México, considerando la información contenida en este trabajo, obligaría a la revisión de las narrativas de la historia reciente, a través de documentación oficial, los repositorios de plataformas documentales, los libros de Historia y materiales para la enseñanza de esta. El desafío está por delante, pero todo apunta a que hay una tarea pendiente en esa reconstrucción historiográfica de la historia reciente, que contemple al menos, la información de los casos paradigmáticos de las violaciones a los derechos humanos que se siguen visibilizando.

\section{México y la justicia transicional: ante su pasado, su presente y su futuro}

La revisión de las agendas de los actores reseñados, desde la construcción de conocimiento, la movilización e incidencia, y desde el Estado, coinciden en tres dimensiones que tienen como horizonte común el fortalecimiento de un Estado Democrático de Derecho: la preocupación urgente de atender en las violaciones a los derechos humanos de la historia reciente, así como el sistema de alta y persistente violencia que aún continua; la necesidad de revisar los mecanismos de transmisión de esos eventos del pasado para que no sean olvidados; y la impostergable lucha contra la impunidad.

Trabajando desde una perspectiva de derechos, como la proporciona la justicia transicional, conlleva desafíos de diferente orden, que deberán ser asumidos desde la sociedad en su conjunto, y si bien no hay un modelo a seguir, lo que queda al final de una revisión de la realidad desde esta perspectiva crítica es asumir, que el presente, el pasado y el futuro se entrelazan en líneas atemporales. Para el México actual, en el cual ha irrumpido la justicia transicional ya no hay vuelta atrás, porque lo que ya se ha dicho no puede esconderse ni ocultarse: la violencia, las violaciones a los derechos humanos y la impunidad. Estas graves problemáticas sociales apuntan a las debilidades en la construcción democrática y las instituciones, y muestran los riesgos, como la profundización de una crisis social y política, y los daños que devienen de la adopción de políticas osadas que no tienen como horizonte claro un Estado Democrático de Derecho basado en los derechos humanos. Así la tarea pendiente es trabajar hacia el rescate de ese pasado, porque el presente lo demanda, si se anhela un mejor futuro.

\section{Referencias}

Acosta, M. (2019, 18 de septiembre). Un espacio de reflexión (Think Tank). Justicia Transicional para México. Animal Político. Recuperado de https://www. animalpolitico.com/justicia-transicional-en-mexico/ un-espacio-de-reflexion-think-tank-en-justicia-transicional-para-mexico/

Ardila, D. (2008). Justicia Transicional: Principios Básicos. Escola de Cultura de Pau. Recuperado de https://escolapau.uab.cat/img/programas/derecho/ justicia/doc004.pdf

Ceja, J. (2019). [Comunicación personal]. 31 de octubre de 2019.

Centro de Investigación y Docencia Económicas y Comisión Nacional de Derechos Humanos (CIDE-CNDH) (2018). Estudio para elaborar una propuesta de política pública en materia de Justicia Transicional en México. Ciudad de México: CIDE y Comisión Nacional de Derechos Humanos. Recuperado de https://www.cndh.org.mx/sites/default/files/ documentos/2019-01/Estudio_Justicia_Transicional_ Mexico.pdf
Cervantes, O. (2016). México en 2000: ¿Transición a la democracia? Revista Consideraciones. Recuperado de https://revistaconsideraciones.com/2016/07/08/ mexico-en-2000-transicion-a-la-democracia/

Comisión de la Verdad del estado de Guerrero (COMVERDAD) (2014). Informe Final de Actividades. México: COMVERDAD. Recuperado de http://congresogro.gob.mx/files/InformeFinalCOMVERDAD.pdf

Comisión Mexicana de Defensa y Promoción de los Derechos Humanos (CMDPDH) (2019). Propuesta ciudadana para la construcción de una política sobre verdad, justicia y reparación. A las víctimas de la violencia y de las violaciones a los derechos humanos. México: CMDPDH. Recuperado de http://www.cmdpdh.org/publicaciones-pdf/cmdpdh-justicia-transcional-2019.pdf

Concha, M. (12 de octubre de 2013). Comisión de la verdad en Oaxaca. La Jornada. Recuperado de https:// www.jornada.com.mx/2013/10/12/opinion/018a2pol 
Gobierno del estado de Guerrero. Poder Legislativo. (2012). Ley número 932 por la que se crea la Comisión de la Verdad para la investigación de las violaciones a los derechos humanos durante la guerra sucia de los años sesenta y setentas del estado de Guerrero. Periódico Oficial del Gobierno del Estado (23). Recuperado de http://congresogro.gob.mx/61/ attachments/article/628/\%EF\% 83\%96LEY\%20 NO.\%20932\%20CREA\%20LA\%20COMISION\%20 DE\%20LA\%20VERDAD\%20(19-DIC-11).pdf

González, M. P. (2013). La Justicia Transicional: Un paradigma para comprender la historia y pensar el futuro. Recuperado de http://mexicoseguridad.mx/ la-justicia-transicional-un-paradigma-para-comprender-la-historia-y-pensar-el-futuro/

Justicia transicional, solución ante violencia en México, asegura Sánchez Cordero. (17 de julio de 2018). La Razón Online / NTX. Recuperado de https://www. razon.com.mx/mexico/poner-a-victimas-en-el-centro-con-justicia-transicional-en-mexico-sanchez-cordero/

Lara, C. (11 de enero de 2020). Segob prepara ruta de justicia transicional. El Sol de México. Recuperado de https://www.elsoldemexico.com.mx/mexico/politica/ segob-prepara-ruta-de-justicia-transicional-4685917. html

Méndez, A, (27 de marzo de 2007). La Femospp se extingue sin conseguir que se castigue a presuntos represores. La Jornada. Recuperado de https://www. jornada.com.mx/2007/03/27/index.php?section=politica\&article $=014 \mathrm{n} 1 \mathrm{pol}$

Meyer, L. (1976). Historia general de México. México: El Colegio de México. Tomo 2. Meyer, L. (1976). Historia general de México. México: El Colegio de México. Tomo 2.

Morales, L.G. (2018). Historia de Morelos. Tierra, gente, tiempos del Sur. Morelos: Universidad Autónoma del Estado de Morelos. Tomo VIII. Recuperado de http://investigacion.uaem.mx/archivos/epub/historia-morelos/historia-morelos-8.pdf

National Security Archive (NSA) (26 de febrero de 2006). Informe Documenta sobre 18 años de "Guerra Sucia” en México Fiscal Especial: Responsabilidad del Estado en Cientos de Asesinatos y Desapariciones. Recuperado de https://nsarchive2.gwu.edu// NSAEBB/NSAEBB180/index2.htm
Okuneva, L. (2010). El glorioso Bicentenario: algunas reflexiones acerca de las particularidades de la historia mexicana. Iberoamérica, 2, 5-13. Recuperado de http://www.ilaran.ru/pdf/2010/Iberoamerica/ IbA_2010_2/Okuneva.pdf

Orduña, E., Sprenkels, R., Juárez, J. (Coords.) (2018). La justicia transicional en perspectiva comparada: Centroamérica y México. México: Centro de Investigaciones sobre América Latina y el Caribe (CIALC) de la Universidad Nacional Autónoma de México (UNAM).

Secretaría de Gobernación (SEGOB) (27 de agosto de 2019). ¿Qué es la justicia transicional? Recuperado de https://www.gob.mx/segob/articulos/ que-es-la-justicia-transicional?idiom $=e s$

Secretaria de Gobernación (SEGOB) (s/f). Sitios de Memoria. Verdad, memoria, Justicia, Reparación y no Repetición. Recuperado de http://sitiosdememoria.segob.gob.mx/

Solalinde, J.A., Jiménez, M. P. y Osorno, D. E. (2016),. Informe de la Comisión de la Verdad sobre los hechos que motivaron las violaciones a los derechos humanos al pueblo oaxaqueño en 2006 y 2007. Comisión de la Verdad de Oaxaca. Recuperado de https://www. dropbox.com/s/olgkklqskg6tmgy/INFORME-FINAL-COMISION-DE-LA-VERDAD-DE-OAXACA. $\operatorname{pdf} ? \mathrm{dl}=0$

Treviño, J. (2018). La justicia transicional en perspectiva comparada: Centroamérica y México. México: Centro de Investigaciones sobre América Latina y el Caribe (CIALC) de la Universidad Nacional Autónoma de México (UNAM).

Valencia, H. (2007). Introducción a la justicia transicional. Recuperado de

https://www.academia.edu/23974119/Introducci\%C3\%B3n_a_la_justicia_transicional_1

Petrich, B. (Diciembre 3 de 2014). La impunidad que subsiste en Guerrero viene desde la guerra sucia: COMVERDAD. La Jornada. Recuperado de https:// www.jornada.com.mx/2014/10/14/politica/008n1pol

Pérez C., J. (2017). La línea del horizonte transicional y los problemas de procesar crímenes de lesa humanidad en México: un análisis de sus documentos clave. Revista Penal y los Derechos Humanos 13, 63-83. 
Pensky, M. (2006). El Pasado es otro Pueblo. Un argumento a favor de los derechos póstumos como limitaciones normativas a las amnistías". En Justicia Transicional: Teoría y Praxis, 113-140. Recuperado de https://books.google.com.mx/books?id=0oYQpI7BhvwC\&pg=PA480\&lpg=PA480\&dq=justicia +transicional+teoria $+y+$ praxis + leer $+e n+l i n e a \&-$ source $=$ bl\&ots $=$ viINGzYUiN\&sig $=$ ACfU3U0v4tNRayd9zm8JNy0vNJx_158Ylg\&hl=es-419\&sa $=$ X\&ved $=2$ ahUKEwjAuNSg 1 K3h Ah VO0 KwKHRxcA_s4ChDoATAAegQICRAB\# $\mathrm{v}=$ onepage \&q=justicia\%20transicional $\% 20$ teoria $\% 20 y \% 20$ praxis $\% 20$ leer\%20en\%20linea\&f=false

Popovski, V. y Serrano, M., (Eds.) (2012). "After Oppression: Transitional Justice in Latin America and Eastern Europe". Tokyo: UN University Press.

Quadratín (3 de mayo de 2016). Difunde Comisión de la Verdad informe final sobre hechos en Oaxaca. Quadratín. Recuperado de https://www.quadratin. com.mx/sucesos/Difunde-Comision-la-Verdad-informe-final-hechos-Oaxaca/

Salvatierra, S., Díaz, A. y Knippen, J., (2018). Derecho a la verdad en México Alcances y limitaciones en casos de violaciones graves de derechos humanos. México: Article 19 Oficina para México y Centroamérica. Recuperado de https://ibero.mx/files/informe-derecho-a-la-verdad.pdf

Secretaría de Gobernación (SEGOB) (6 de enero de 2020). Presenta Gobernación Informe de fosas clandestinas y registro nacional de personas desaparecidas o no localizadas. Recuperado de https://www. gob.mx/segob/prensa/presenta-gobernacion-informe-de-fosas-clandestinas-y-registro-de-personas-nacional-de-desaparecidas-o-no-localizadas 